\title{
The hospital building as project and matter of concern: the role of representations in negotiating patient room designs and bodies
}

Article

Accepted Version

Harty, C. and Tryggestad, K. (2015) The hospital building as project and matter of concern: the role of representations in negotiating patient room designs and bodies. Engineering Project Organization Journal, 5 (2-3). pp. 95-105. ISSN 21573735 doi: https://doi.org/10.1080/21573727.2015.1046047 Available at https://centaur.reading.ac.uk/69998/

It is advisable to refer to the publisher's version if you intend to cite from the work. See Guidance on citing.

To link to this article DOI: http://dx.doi.org/10.1080/21573727.2015.1046047

Publisher: Taylor \& Francis

All outputs in CentAUR are protected by Intellectual Property Rights law, including copyright law. Copyright and IPR is retained by the creators or other copyright holders. Terms and conditions for use of this material are defined in the End User Agreement. 


\section{CentAUR}

Central Archive at the University of Reading

Reading's research outputs online 


\section{Abstract}

Mock-ups, scale models and drawings are ubiquitous in building design processes, circulating between various stakeholders. They contribute to the gradual evolution of design, but what else can specific material forms of representations do for the building design and project? The full-scale model of a hospital single-bed room can be different in terms of detail and medium, but in what sense might it perform different and similar functions? The mobilization of multiple forms of representations and visualizations suggest that design materialization might have several important roles to play in negotiating the building design and project, including the exposition and resolution of controversy concerning size of spaces and bodies. The paper compares the use of two different forms of representation of the same imagined space-a single-bed room in a hospital, and produced for similar purposes - to ascertain what the optimum (or minimum) spatial requirements should be to allow effective care of patients. The first representations are physical mock-ups of a single-bed room for Danish hospitals where actual medical and logistical procedures are simulated using real equipment and real people. The second is a three-dimensional augmented reality model of a singlebed room for a new hospital in the UK, using a Cave Automatic Virtual Environment where the room is reproduced virtually at one-to-one scale, and which can be explored or navigated using headtracker technology and a joystick controller. Drawing on Latour's concepts of matters of concern and matters of fact, we compare these two cases to provide insights into the way different media produce specific senses of the design or imagined space, with consequences for on-going design work, and for the settling of controversy over the sizes of spaces and bodies.

Keywords: Hospital design, matters of concern, simulation, space

Introduction

The cover image of the book 'Reassembling the social' (Latour, 2005) depicts a construction site with the people, equipment, building materials and scaffolding. In front stage, two men are having a conversation over what seems to be a document, perhaps it is a plan or a drawing for a building. Behind them and closer to the perimeter of the construction site several armed soldiers keep a watchful eye on the surroundings. The building site seems controversial and many human and nonhuman entities are required to hold the project together. When the building has been completed, it might be used and taken for granted by people who pursue their own projects.

We might say that the building has become a 'matter of fact', a non-controversial, stable thing. However, with Latour $(2005 ; 2008$ a) we might continue to consider the building as 'matter of concern' rather than as a 'matter of fact', that is, as an ongoing accomplishment: from its inception, during construction and in use. A building 'is not a static object but a moving project' (Latour and Yaneva, 2008) even after it has been handed over to its clients and users. Brand (1995) illustrates this in a beautiful way in his book with the aptly chosen title 'How buildings learn: What happens after they're built'. Buildings are often rebuilt, 'more is spent on changing buildings than on building new ones' (Brand, 1995 p. 5). New opportunities, issues and concerns emerge along with changes in technology, economy, policy, fashion and more specifically, the building's stakeholder environment and context of use. As a matter of concern, the building and project is never finalized. 
But often the activities around building projects are concerned with reducing uncertainty and increasing stability and predictability; whether through project management techniques, budget control, risk assessment, use of collaborative IT tools to improve information sharing, managing the various stakeholders around a project and so on. The creation of various representations (physical, digital, visual, numerical) of the eventual building which reflect its future shape and state is similarly often oriented towards increasing certainty. Much of the construction management literature is concerned with developing new methods and tools to control these various complexities. However, there are other perspectives which challenge this, instead attempting to expose the inherent asymmetric power relations and non-rational bases through which project management techniques are constructed, or which explore the emergent and unforeseen consequences of adopting supposedly objective and uncontroversial methods and tools for project management improvement. Several authors have questioned the neutrality of the methods and tools by pointing to their cultural role in rituals, power effects and role as managerial instruments for domination (e.g. Cicmil and Hodgson, 2006; Van Marrewijk, 2007; Sage et al., 2010 ; Clegg and Kreiner, 2013).

Specifically focusing on the role of representations in projects, recent work has drawn on Science and Technology Studies (STS) approaches to better understand the interactions and networks around the heterogeneous actors, artefacts, interests and routines which constitute construction project work. Studies have focused on visions and goals (Harty, 2008; Tryggestad et al., 2010), design practices (Yaneva, 2005; Whyte et al., 2007; Ripley et al., 2009; Våland, 2010), innovation (Harty, 2005 Harty), project management roles (Georg and Tryggestad, 2009), business performance (Justesen and Mouritsen, 2009; Kjellberg, 2010), design spaces and relative visibility for the case of building design and integrated chip design (Kreiner and Tryggestad, 2002). They all demonstrate that attempts to translate a building design into an actual building require the mobilization of a whole chain or cascade of devices for explorations of designs and options, often involving different knowledge claims, emerging concerns and controversies concerning the feasibility and relative value of design and decision options. We build on these studies here by discussing two cases about the use of representations in an attempt to reach closure and settle controversies, to turn matters of concern into matters of fact. Both cases involve concerns over the sizes of patient rooms in the design of new hospital buildings, and both involve a range of representations, actors and interests.

The concept 'matter of concern' (Latour, 2005) helps to unpack and illuminate the uncertain conditions and conflicting knowledge claims and controversies that the building projects entail. The concept's emphasis on such uncertainties is in line with actor-network theory's (ANT) rejection of the fact/value distinction in the natural and social sciences and the assumption that objects such as a hospital building can be represented in design drawings, models and simulations in a value neutral manner (Latour, 2004; Tryggestad et al., 2013). Artefacts, including buildings, design representations and visualizations are not just considered as neutral and passive (Latour, 1986). Whatmore (2009) suggests that knowledge controversies can be generative events, accomplished through the invention and use of tools and models for representation. We put emphasis on revealing the more active role of technology, for example, in the co-production of design knowledge and user identities.

Therefore we position the building and project not as a matter of fact and thus a more static, simplified and abstract rendering, but as a matter of concern which draws in other concerns, knowledges and representations. Callon and Rabeharisoa (2003) describe how lay people and emerging concerned groups can make invaluable contributions to expert knowledge about patients' health condition and treatment. During this process of knowledge production they can also become stakeholders capable of formulating new strategic options and stakes. In the context of care (Pui de 
la Bellacasa, 2011) and in particular when considering matters of concern in health care provision, several contributions have revealed how patients can be involved in design processes and also become active co-producers and designers of health care provisions and technologies (Mol, 2002; Langstrup Nielsen, 2005; Moser, 2008; Reijonen and Tryggestad, 2012).

Designs can be considered as matters of concerns that are distributed and produced in heterogeneous networks consisting of both humans and technologies (Latour, 2008b). Akrich (1992) revealed how a technological design can fail-a process of displacement and de-scription of technical objects-because of its inscriptions and representations of users. In this case, the users inscribed into the technological design were simplified while the end users in flesh and blood were excluded along with their different requirements and concerns. Complementary to this, de Laet and Mol (2000) showed that a more flexible and 'fluid' technological design could be more robust and stand a better chance of success because of its ability to adapt to different users, concerns and situations of use. This challenge of designing for multiple and/or unknown future users resonates strongly with debates over how to incorporate flexibility and adaptability into buildings with long life cycles, or how to embed shared technology platforms across the multiplicity of firms involved in a construction project.

Here we focus specifically on hospital constructions, as an example of a complex endeavour and building project, and on specific forms of representation-full-scale mock-ups-and the ways in which they participate in negotiating the future hospital and its end users as 'matters of concern'. The remaining parts of the paper are organized in the following way: the next section discusses the methods and case-based approach, followed by the two cases of hospital building projects from Denmark and the UK, respectively. Both cases account for the emerging concerns related to the size and design of the 'single-bed patient room' and the generative role of full-scale mock-ups in this process.

\section{Methods}

Our inquiry is built around two distinct but complementary cases, thematically connected through the concept and design of a 'single-bed patient room' in hospital building projects in Denmark and the UK, respectively. The approach to both method and analysis is processual (Pettigrew, 1997; Hernes and Weik, 2007) and specifically aims to reconstruct the complex chains of events and associations playing out within the cases and to account for the ways in which representations are implicated in generating concerns or reaching closure about design (Whatmore, 2009). In adopting this approach, we are inspired by Latour's (1987) method of analysis to 'follow the actors' tracing the associations between humans and non-humans such as various forms of design representations (Harty, 2008). Both cases mobilize this approach to focus on the emergence and translation of concerns through engagement with different forms of representation.

The two case studies differ in terms of the representations they account for and analyse, and this is a key part of the contribution they collectively make. For the Danish case, a series of traditional forms of design representations were mobilized, including full-scale physical mock-ups of a single-bed patient room and various documents. In the UK case, the authors had unique and novel access to the production and use of virtual immersive representations within a university virtual research laboratory. These representations were used as an experimental alternative to the type of physical mock-up used in the Danish case. 
Given these differences, the methods employed for the collection of empirical material are consistent but not symmetrical. In the first case, they involve visits to the design lab and the design exhibition at Region South, analysis of reports and images documenting the design process, interviews, conversations and meetings with members of the project management offices, including project management at Region South and the Capitol Region. These comprise a broadly ethnographic form of enquiry (See e.g. Pink et al., 2012). The data for the second UK case also involve attendance at design meetings and informal interviews with the project team, but is centred around a series of video-recorded and direct observations of design review activities within a virtual reality facility at the University of Reading. This approach draws on video-based methods in being able to view and review these recorded activities (Heath et al., 2010). Across the cases, the methods are complementary and consistent with both STS-oriented studies and those which interrogate the non-rational and non-neutral qualities of representations.

The intention is not to position the cases as comparable or symmetrical, but rather to show how in these different contexts the use and function of representations is bound up with the production, transformation and (in some instances) resolution of concerns over design.

While both cases are emerging we present preliminary findings concerning how different technologies of representation such as 2D, 3D and full-scale 4D 'physical' simulation models participate in the materialization and valuation of the single-bed patient room design. Both cases account for the simulations and demonstrations of how large the room should be, the further design requirements of other things such as equipment and furniture that emerge in the design process and finally, the different materialities that are mobilized in constituting the room and designed space.

Case 1: how large should the room be? The Danish single-bed concept

The Danish state has established a programme ('Kvalitetsfonden') with approximately 42 billion DKK dedicated to fund hospital construction projects within the public health care sector and regions. It is one of the largest societal infrastructure investments in Denmark ever. Currently there are some 16 hospitals on the drawing board or under construction within the programme. The projects are of different types, ranging from mega projects such as the large green field investments in the new 'super hospitals' within the major cities and regions in Denmark, the largest projects with a budget sum around 6.5 billion DKK, to upgrading of existing hospitals. Each hospital project within the program must pass the state's screening body, the 'Expert panel'. It is an iterative process through which the region's original project proposals are evaluated and eventually refined before dedicated funds are allocated to a hospital project.

The case of the Danish single-bed concept consists of two vignettes that reconstruct the evolution of the design concept and the related concerns and controversies they generate. The first vignette accounts for the Expert panel's concept and evaluation of the single-bed patient room. The second vignette shows the different ways the design concept is enacted and negotiated between the regions and the Expert panel. Together, the two case vignettes show how the single-bed concept is represented, visualized, re-conceptualized and negotiated through time and space. The case description accounts for different forms of representations such as numeric calculations/budget estimates, comparative case analysis of different types of rooms and sizes, and full-scale physical mock-ups and how these individually and together contribute to the design concept in relation to future use and users. 
Economic valuations of room size: the hospital programme and budget

In their report, the Expert panel (2008) considered the design of the single-bed patient room in terms of how large it should be. The Expert panel did not question the premise and value that the room should be a single-bed rather than a multi-bed room. Instead, there were further considerations about the maximum size it could be. The room should not be too large because that will incur unnecessary costs both to the individual hospital's project budget as well as to the future hospital facility and operating budget. The Expert panel's future budget concerns are further translated into an estimation of the appropriate size for the single-bed room: 40 square metres is considered too large, and 33-35 square metres is considered appropriate, for all hospitals and projects in the programme. In order to qualify their estimation of the appropriate size and design standard, the Expert panel uses a production cost calculus for the construction of a single-bed room that demonstrates the economic effect of a too large 40 square metres room. The economic calculations of the production costs and the two cost budgets (for the project and hospital in operation, respectively) help the Expert panel to explicate the value of a cost-efficient hospital design and to define its appropriate size. The question and concern about the appropriate design and size are thus resolved through the economic calculation. The report further helps to visualize this economic design value. More implicitly, the single-bed concept also takes other values and concerns into account such as infection risks and the prospective patients' need for privacy. However, and to be further described below, these different design values and concerns are only temporarily resolved by the Expert panel's economic calculations and report.

Juxtaposition of clinical and economic valuations of room size

At the Capitol Region a project team was established during fall 2009. Among its tasks was to consider the question of how large a normal single-bed patient room should be. The management and team were well aware of the Expert panel's report and view. Instead of subscribing to the Expert panel's design, the project team raised new questions concerning what the design might have excluded or not considered sufficiently well. These questions and issues included values such as the patient's clinical treatment and the staff's work conditions. The budget and efficiency concerns explicated by the Expert panel were not considered irrelevant but rather as one among many relevant concerns that the design needed to take into account.

In order to sort out the design issues and possible implications in a more precise way the project team used a comparative case method. The team did not limit their empirical inquiries to their own hospitals but assembled data and empirical material from existing hospital designs in Denmark and abroad (Norway in particular). In this way the team could benchmark the new and smaller design standard proposed by the Expert panel with a broad range of cases and experiences from hospital designs in use or under construction. The case material showed that the room size for a majority of the hospitals and projects in their study was larger than the Expert panel's recommendation and closer to 40 square metres. In addition, the case material included a prognosis concerning the size of the future patient's body. The average size of the body was expected to increase quite significantly with further possible design implications concerning the size of the patient room. In the resulting report (2009), new concerns were raised that were at odds with the Expert panel. For example, the team and region argued that it was necessary to take into account each particular hospital project before deciding on a specific room size. However, the report also concluded that the health and safety of the patient might be at risk if the Expert panel's area standard is established as the norm. In terms of the specific design implications the report concludes that the Capitol Region is opting for a 
larger room size than the Expert panel and is willing to accept higher costs in their hospital construction projects and in operations in order to secure the design for the future patient and larger body. Like the report from the Expert panel, the report from the Capitol Region uses cost and budget estimates to qualify their conclusion regarding the design. But unlike the Expert panel, the region uses additional empirical materials and experiences from current hospital design and projects as well as extrapolations and scenarios about the future patient and body size.

The project management at Region South was informed about the Expert panel's 33-35 square metres design standard but uncertainties still prevailed. The design would perhaps be economically feasible, but would it also be clinically feasible? In order to sort out the question about the clinical feasibility, project management at Region South decided to contract the task to a nearby design laboratory, the Center for User Driven Innovation. The laboratory consisted of clinical professionals with training in ethnographical methods and action research. The laboratory approached the task by building a full-scale physical mock-up of a patient room according to the design standard and size set forth by the Expert panel. The room was further equipped with a standard hospital bed and furniture, medical equipment and a living person playing the role as patient. A number of other persons played the roles of nurses and doctors. Prior to the simulation all persons in the room were instructed according to a manuscript which included the simulation of a heart attack along with immediate treatment on site. The simulation was filmed and further documented with photographs and feedbacks from those involved. A report concluded the simulation (Center for brugerdrevet innovation, 2010).

The simulation revealed frictions between bodies and between bodies, equipment and furniture when in motion during the heart attack and treatment. The main conclusion from the report concerns the context of treatment: if the patient or other persons in the room are larger than average, then the Expert panel's design standard might hamper swift and adequate treatment. This is especially so in acute situations such as heart attacks in which medical equipment must be mobilized together with a number of medical professionals. Extra time for the logistics will be required due to the limited space. In contrast to the report from the Capitol Region, the report from Region South does not include economic calculations. However, there were instances of economic judgements of a more qualitative nature. For example, the report points out that it might be possible to accommodate concerns for the patient's health and safety within the limited space implied by the Expert panel's design standard. This, however, will require further investments in new technological solutions, equipment and furniture in particular such as the 'intelligent bed' and robotics for logistics and waste management. The report does not attempt to estimate the extra economic costs associated with these mitigating investments.

Region South and Capitol Region are two of the five members of a national umbrella organization, 'Danske Regioner'. In their report Danish Regions (2009) articulated further concerns about the Expert panel's 33-35 square metre area standard. It is not only considered too small and inflexible in terms of future use, users and needs, but also more costly than a 40 square metre room. The Danish Region recognizes - ceteris paribus - that the sum of the project budget will increase with a larger 40 square metre area. But they argue that hospital design will be more costly with a smaller 33-35 square metre area due to the mobilization of another budget for the hospital facility in use. When the two budgets are added it is possible to calculate the 'total economy' for the project and facility. The Danish Regions mobilize the 'total economy' to suggest that the savings obtained over the project budget due to the smaller area standard does not resolve the economic matters of concern and eventually, it could end in a more costly solution when viewed as a 'total economy'. As an example, the Danish Regions articulate the spatial-economic connections between the single-bed 
room and the adjacent spaces for examination and conversations with the patients and for relatives in need of place to stay overnight. The 'saving potential for these other functional areas are included in the regions' dimensioning [of the 40 square meter single-bed room]' (p. 4, translated from Danish). The savings potentials and benefits are thus related to the adjacent spaces and functions for the hospital in operation: a larger standard area for the single-bed room permits these areas to be made smaller. Thus with the help of the calculation of the 'total economy' the connection to the adjacent areas outside the single-bed room is revealed. In this way, the Danish Regions reframe the economic concerns so that the larger patient room is no longer part of the problem but is rather to be considered an important part of the 'total' solution both in terms of design as well as economy.

However, the Expert panel (2008) already defined what the proper 'total' solution should be with the help of another metric. The relation between the single-bed room and the adjacent areas is defined with the help of the metric called the 'brutto/netto factor'. This factor estimates how many brutto or total square metres (including space for technical installations, walls, stair cases and adjacent rooms for staff, storage and more) are required for obtaining one square metre of floor space in a patient room. The Expert panel recommends a factor of 2.0. The Danish Regions question the Expert panel's recommendation and respond with own inquiries of hospital projects in Scandinavia and Norway. They contract the well-reputed Danish architect firm C.F Møller for the task. The Danish Regions point out with reference to the findings reported by C.F. Møller that the recently built hospital Nye Ahus in Oslo was originally planned with a 30 square metre single-bed room and a brutto/netto factor of 1.97 but ended with 2.17 and adjacent areas for 'personnel that were very small and there were no space for meetings/conference and teaching' (p. 5). For St. Olav in Trondheim phases I \& II are accomplished with 2.19 and 2.06, respectively, while the new university hospital in Oslo, Rikshospitalet, operates with a brutto/netto factor of 2.49. The Danish Regions thus supplement and contradict the Expert panel by advocating a less restrictive set of estimates, measurements and standards for the hospital projects and single-bed rooms. Danish Regions conclude that the 'brutto/netto factor' should be at least 2.1, and that the Expert panel 'undermines' ( $p .7)$ the shared ambition to develop flexible hospital designs and building constructions for the future.

As suggested above, one important and prevailing concern is about the future patient and body size. This issue and concern is re-articulated by Statens Byggeforskningsinstitut (2012) with the help of simulation of transportation of the patient inside the single-bed suite. It combines full-scale physical mock-up and two-dimensional drawings that together reveal the large patient and body in motion in interaction with the equipment and clinical staff. The report departs from the observation that the existing hospital buildings are not designed to take these patients' space requirements into account, nor able to provide sufficient space for the clinical staff. The full-scale mock-up included people in the roles as patient (with body weights of 205, 250 and $300 \mathrm{~kg}$ ) and clinical staff from Odense University Hospital along with equipment such as bed, wheel chair and toilet. The report translates these simulations and images into numbers that define the recommended minimum space requirements for different types of patients and medical conditions, ranging from those that are completely able to move themselves to those that are highly dependent on support from clinical staff and special equipment such as mobile lifts and transportation devices. The recommended minimum size requirement for the bedroom and bathroom varies significantly depending upon the patient's medical condition and (in)ability to move: for the bedroom between 11.5 and 32.5 square metre, respectively and for the bath room between 9 and 18.5 square metre, respectively. In total (bedroom + bathroom), this ranges between 20.5 and 41 square metre, respectively. This difference in open floor space requirements is related to a complex set of interdependent material support structures (equipment and bodies in motion, both patient and staff) and spatial arrangements. For 
example, in moving the very large patient with a medical condition involving significantly reduced mobility, two beds and four clinical staff for transportation might be required which in turn will require more open floor space. A design assumption based on a single-bed patient room with average sized patients with good mobility might not suffice in this situation. Unlike the other reports, the Statens Byggeforskningsinstitut (SBI) report does not address the Expert panel's singlebed room area standard directly or the associated controversy but could potentially make an important contribution to the debate in terms of enacting the spatial specificity and multiplicity of the patient and end-user body ( $\mathrm{Mol}, 2002)$. The report does, however, address those involved in the current Danish hospital projects with the aim of providing them with design recommendations to better take the very large patients into account. For example, the report's findings seems to imply that existing hospital projects should be careful in taking the variability of size weight and medical condition of the citizen-patient into account. Related to this, it is also important to take the variable sizes, types and numbers of beds and equipment into account.

\section{Case 2: Is the room big enough? The UK case}

This case involves the design of a new specialist hospital in the UK. Currently, the project is in the late stages of tendering, with the announcement of the successful consortium due later in the year. The requirements for the hospital are that all in-patient accommodation has to be single-bed room with en-suite facilities. This is in line with a general shift in opinion within the National Health Service (NHS) in the UK towards the advantages single-bed rooms offer in terms of patient privacy and dignity, control of hospital-acquired infection and access for visitors. But single-bed room only accommodation is unusual in the UK-the first all single-bed room NHS hospital opened in January this year. Various other requirements were specified about natural daylight penetration and visibility of patients from nursing stations, and these presented the design and construction consortia tendering for the project significant challenges in terms of design, but also in communicating to the NHS Trust client that their design fulfilled those requirements.

Our involvement as researchers in this particular case begins with discussions with one of the bidding consortia-'Consortco' - to explore whether advanced virtual reality technologies could be used to show the client that their design fulfilled, and indeed exceeded the requirements. For the upper floors of the hospital where the in-patient accommodation is located, the design they had developed had an elliptical shape with a central light-well, allowing single-bed rooms to be placed on each side of a corridor and to have external windows (facing either outward or into the light-well) extending around the building envelope. This maximized natural daylight allowed good visibility of several rooms from each nursing station in the corridor, and produced an impressive design. However, this presented some issues. Although not necessarily a firm requirement, the NHS produces various guidelines for hospital design - the Health Building Notes and Health Technical Memoranda. The nature of the design meant that the single-bed rooms were all slightly different (due to the curve in the outer wall) and slightly smaller than the guidelines. So there was a challenge to convince the client that the rooms were big enough, not just for in-patient accommodation, but also for access by crash teams in the case of emergencies.

One way to demonstrate this is through building physical, 1:1 scale mock-up (as in the Danish case above) but this is very costly-perhaps $£ 100,000$ per model. Physical models are also inflexible-if changes are suggested this would require significant rework. So an exploratory conversation was begun with the University of Reading to see whether the immersive virtual reality facilities within the Visualisation and Interactive Technologies Centre (VIT-C) could be used as an alternative to 
physical models to establish that the size of the single-bed rooms was adequate. In particular, the Cave Automatic Virtual Environment (CAVE) presented opportunities to show the single-bed room model in an immersive environment, with a 1:1 scale. The CAVE works by simultaneously projecting images of the model onto three walls and the floor or an approximately $4 \mathrm{~m}^{2}$ space, using active glasses to produce the 3D effect, and head tracking to coordinate the four sets of images. The particular ambitions of Consortco were significant; a decision had been made that the design would be developed in a 3D/building information modelling (BIM) environment, so a more-or-less complete model of the hospital had been produced. The initial conversations were therefore to establish how technically difficult (and hence expensive) would it be to take existing BIM models and transfer them into the CAVE, and to see whether they would be of a high enough quality to show the client, be able to demonstrate the scale and configuration of the single-bed room accurately enough to establish that they were big enough, and be user friendly and intuitive enough for a nonconstruction client to understand and engage with. After establishing that the models could be transferred, a total of seven separate sessions were held in the CAVE, culminating with the visit of seven client representatives to review the models. For the purposes of discussion, we will divide these into two periods: initially establishing viability, and increasing scale and scope of the simulation.

Once the technological possibility of displaying the existing models within the CAVE was established, the next step was to check whether the technology, and the simulation, would be a suitable medium for the client demonstration. An initial session was set up where several senior members of the bid team came to the CAVE to assess the single-bed room model. The session exposed a number of interesting issues around the use of the technology, the simulation itself and the design of the room.

As the session began, it became clear very quickly that some time was required for the users to 'orient' themselves to the CAVE itself (a dark space enclosed on three sides), to the peripheral artefacts (wearing the stereo glasses, the head tracker and protective footwear) and to the previously un-experienced 1:1 perspective of the model. For instance, proximity to the head tracker (from the position of which the hardware works out how to synchronize the four separate projectors) is needed to keep the correct perspective of the model, and the users quickly worked out that they needed to stand close to the person who was using it, and that it had to be passed around the group to make sure everyone was 'seeing the same thing'. The tension between the scale and size of the simulation - a reasonably large room - and the physical space of the CAVE itself-which is much smaller-became apparent, but this was a different sort of materiality than that seen in the Danish case. At various points, several of the group, fully immersed in the virtual space, walked into the CAVEs projection screens (much to the amusement of the others), forgetting that they were in a smaller space than the virtual room. This was the materiality of the CAVE pushing back onto the 'virtual materiality' of the simulation.

But the users quickly became familiar with both the CAVE itself, and what they were seeing, and the discussions moved onto aspects of the 'fit for purpose-ness' of the simulation. It was agreed that it would be possible, and that the simulation gave a clear indication that the room was indeed 'big enough'. Thus a matter of concern-would it work-was shifted to something else. But this was not, arguably, into a matter of fact, but more into a proliferation of other matters of concern. There were several discussions about how specific aspects might be refined-both in terms of what the 'process' of showing the client the models would be like (free navigation or predefined route? Leave them to it, or provide a 'guided commentary?)', and in refining some parts of the model (such as adding more textures to objects, making some objects (such as bed-tables) moveable and so on). The simulation also raised unexpected matters of concern. For instance, on entering the en-suite 
bathroom of the single-bed room, they were surprised to see so many different fixtures (grab rails, etc.), many of which seemed to be in the wrong location. This provoked a discussion of why that was-a problem with the perspective of the simulation? An error in the model? A mistake that was not picked up through the computer aided design model on the computer screen or printout? These concerns made connections between this particular simulation and the design process behind it, and to ways to re-design the layout of the bathroom to improve it.

At the close of the meeting, several follow-up sessions were planned, to get the modellers and visualizers working on the project to come to see the model, and work out what to do to add the required refinements. Over the course of these sessions, the simulation not only evolved to incorporate these finer details, but also the scope and scale of the exercise-which was originally just to establish with the client that the room was big enough-escalated significantly. The first request was to expand from a single-bed room to a corridor with four rooms on each side. This would provide a better sense of how the rooms fit into the overall design, and would establish lines of sight from nursing stations - the lack of visibility being one of the drawbacks of single-bed room only designs. Then it was decided to also produce a simulation of one of the operating theatres complete with all the medical equipments, to show the client the efficiency of the design, and finally to model the main entrance and atrium - very large spaces which were the centre piece of the design. This would allow the client not only to get a sense of the space, but also to 'walk through' and explore these large open spaces. This represented a significant shift in the role of the simulation-from a tool to address a particular matter of concern - the size of the room-to an integral part of the bid and a way of demonstrating commitment to client engagement, embracement of innovative design technologies and the impressiveness of the overall hospital design itself. This also showed how the specific matter of concern became re-connected to the rest of the hospital design, through simulating corridors, lines of sight, signage systems in the main areas, and developing a 'virtual tour' and commentary to perform when the client visited. There were other connections established, notably the inclusion of a display of pictures of previous incarnations of the hospital (which began as temporary TB sheds) on the corridor linking the main entrance and atrium, to establish the new design's association with the hospital's legacy.

\section{Discussion}

The two cases demonstrate that physical spaces such as the size of the single-bed patient room can become matters of concern. By 'following the actors', our analysis reveals the mechanisms implicated in this process. When room size becomes a matter of concern it happens through a process that involves a whole array of different representations such as full-size mock-ups, budgets and design drawings. The process and mechanisms at play do not simply work to reduce uncertainty and stabilize designs. As suggested, the process is a much more generative one in the sense of spurring new inquiries and problematizations of existing design solutions and the visualization of new design options. New actors and concerns emerge, as in the case of the spatial requirements for the very large and more or less mobile patient groups. In the Danish case, initial concerns about economic space - that is, the cost to size ratio of the room-morph into further concerns about the spatial needs and requirements for these very large patients. In the UK case, a concern over specific aspects of visibility becomes transformed into broader debates on the connections between different parts of the hospital design. But whilst the cases demonstrate different emerging concerns, whether this can be attributed specifically to the different representations mobilized, or to the broader differences in actors and materials involved in each case is difficult to establish. It is clear, however, that the representations are generative in terms of multiplying matters of concerns and 
the number and types of actors and stakes to take into account. Matters of concern are not problems to be solved, but resources that enable the building project and programme to acquire new knowledge about its relevant stakeholder environment and their important contributions.

While both cases use full-scale mock-ups to simulate the single-bed room design, there were also important differences in terms of the material and physical set-up. In the UK case, the physical setup of the virtual simulation allowed further exploration of links between the room and the building envelope such as the outer curve and the view from nursing stations or reception desks in the atrium. In the Danish case, the physical simulation did not produce further concerns and links between the room and the building envelope. Instead, the concerns remained inside the room's spatial boundary and were taken care of through further refinements of the interior design, for example, in the form of more advanced and costly furniture and technological installations. Compared to the Danish case, the UK case produced more and closer links to the building envelope and the overall hospital design and concept. The links and boundary of the single-bed room can thus be considered to be produced in different ways perhaps due to the different methods of design representation and visualization. The boundary appears to be more open and flexible in the UK case.

However, the explanation of this difference can be developed further by considering additional forms of representation and visualization. The Danish case suggests an important role for budgets in making the boundary less open and flexible. Equipped with the programme budget, the Expert panel is prompted to articulate a concern about an economic size for the single-bed room. An economic (cost) boundary is drawn for what constitutes a feasible design and room size. In a more subtle way the economic calculations and design standards also inscribe a particular 'economic and normal' patient, in terms of body and size. This in turn produced a whole array of additional visualizations, representations and clinical concerns among the regions and prospective project and hospital owners. In the physical mock-up and simulation these clinical concerns are delimited to focus on the interactions and the treatment taking place inside the economically feasible patient room. In the Danish case it thus appears that the room's eventual links to the building envelope and the overall hospital design and performance become relatively more difficult to explore due to this array of interlinked representations and concerns. This circumstance is also one of the emerging concerns expressed by the Capitol Region, and by the national umbrella organization 'Danish Regions' (2009) when arguing for a 'total economy' for the hospital. By contrast the UK case evolved to be much more concerned with flow and joining up and connecting to what begun as disparate, separate spaces. Throughout these simulations, there was no substantive discussion of cost or budgets. These discussions would, of course, have been taking place elsewhere, but remained separate from establishing and developing the role of these particular simulations.

There are further interesting differences in the specific materialities of the simulations. For the Danish case the physical simulation produced a concern about friction between bodies and things in motion where the room placed physical constraints on the ability to perform necessary activities within it. The UK case had no such physical constraints to the model itself, but the materiality of the CAVE technology did play a part, whether through the necessity of glasses and the head tracker, or through 'forgetting' the physical limitations of the space and bumping into the projection walls.

Both cases indicate the ways that people and things are drawn into the discussions, mobilized within the unpacking of matters of concern. But neither demonstrates a straightforward movement towards fixity, closure and the establishing of matters of fact. New visualizations, bodies and implications for budgets open up new concerns, such as the connection of a room to the rest of the hospital, or the friction between the bodies in the standard single-bed room. This does not mean that the processes described here are un-productive; rather that the exploration of matters of 
concern, the enrollment of new actors and artefacts, and the on-going debates and discussion are central to the development of the eventual physical hospital space. Rather than see concerns as problems requiring speedy resolution, we would content that the acceptance and opening up of matters of concern is an integral part of the activities of design representation.

\section{Conclusions}

Both of these cases are rife with matters of concern; initially over room sizes, but then over suitability of various forms of representations; simulations, budgets and political implications, ways to impress clients and so on. Both cases demonstrate how representations addressed, but also raised, such matters of concern, and that the representations were central to holding things together, but also not disconnected from other issues, debates and spaces.

In contrast to the UK, the Danish case pointed to the role and importance of the budget and the 'matter of fact' quality of the economic patient, patient room and size. However, the Danish case also suggests that there are costs associated with such premature attempts to reach closure. Other important concerns such as clinical treatment and the room's links to the building envelope and the overall hospital design and performance might be disregarded. A particular controversial issue concerns the Expert panel's room size standard in the context of spatial requirements to accommodate very large patients. The controversy has also changed in character, from questioning and testing the feasibility of the design standard in the context of clinical treatment of an acute situation with average sized bodies, towards a more specific simulation and inquiry into the spatial requirements posed by the very large patient and body. Taken together this cascade of various material forms of representations, simulations, visualizations, tests, demonstrations and numeric translations participate in enacting the body multiple (Mol, 2002) in terms of the spatial specificity and multiplicity of the patient and other end-user bodies. In this sense, the two cases complement each other by showing that physical space and size matter and that they matter in different ways in building design and health care depending upon how the boundaries around a particular design and object are drawn. The different forms of representation and visualization play important generative roles in drawing more or less open and flexible design spaces for the present hospital construction project and in negotiating what end users, bodies and activities for the future hospital to accommodate. They are central parts of the 'on-going accomplishment' of the hospital as project and matters of concern.

Insofar as our study suggests that concerns are contingent on the methods and forms of representations in use, the study also opens up avenues for future research. At present we can imagine that different concerns could have emerged, if, for example, a Danish hospital construction project used the UK-based virtual lab or even perhaps if there was stronger governmental actors or national standards in a UK case. Future research and additional case studies could inquire further into these contingent matters of concern in connection to design representations, both within health care and other design settings.

\section{References}

Akrich, M. (1992) De-scription of a technical objects, in Bijker, W.E. and Law, J. (eds.) Shaping Technology, Building Society: Studies in Sociotechnical Change, The MIT Press, Cambridge, MA, pp. 205-24.

Brand, S. (1995) How Buildings Learn: What Happens After They're Built, Penguin, Middlesex. 
Callon, M. and Rabeharisoa, V. (2003) Research "in the wild" and the shaping of new social identities. Technology in Society, 25, 193-204. doi: 10.1016/S0160-791X(03)00021-6

Center for brugerfokuseret Innovation. (2010). Report, 'Test af fremtidens patientstue, Nyt OUH'.

Cicmil, S. and Hodgson, D. (2006) Making projects critical: an introduction, in Hodgson, D. and Cicmil, S. (eds.) Making Projects Critical, Palgrave Macmillan, New York, pp. 1-28.

Clegg, S.R. and Kreiner, K. (2013) Power and politics in construction projects, in Drouin, N., Muller, R. and Sankaran, S. (eds.) Novel Approaches to Organizational Project Management Research.

Translational and Transformational, Copenhagen Business School Press, Copenhagen, pp. 268-93.

Danske Regioner. (2009) Report, 'Danske Regioners bemærkninger til de anvendte forudsætninger I eksperpanelets screeningrapport'.

Georg, S. and Tryggestad, K. (2009) On the emergence of roles in construction: the qualculative role of project management. Construction Management and Economics, 27(10), 969-81. doi:

10.1080/01446190903181096

Harty, C. (2005) Innovation in construction: a sociology of technology approach. Building Research \& Information, 33(6), 512-22. doi: 10.1080/09613210500288605

Harty, C. (2008) Implementing innovation in construction: contexts, relative boundedness and actornetwork theory. Construction Management and Economics, 26(10), 1029-41. doi:

10.1080/01446190802298413

Heath, C., Hindmarsh, J. and Luff, P. (2010) Video in Qualitative Research, Sage, London. Hernes, T. and Weik, E. (2007) Organization as process: drawing a line between endogenous and exogenous views. Scandinavian Journal of Management, 23(3), 251-64. doi: 10.1016

Justesen, L. and Mouritsen, J. (2009) The triple visual: translations between photographs, 3-D visualizations and calculations. Accounting, Auditing and Accountability Journal, 22(6), 973-90. doi: 10.1108/09513570910980490

Kjellberg, H. (2010) Struggling to perform a warehouse: buildings as symbols and tools. Construction Management and Economics, 28(6), 675-94. doi: 10.1080/01446191003702476

Kreiner, K. and Tryggestad, K. (2002) The co-production of chip and society: unpacking packaged knowledge. Scandinavian Journal of Management, 18, 421-49. doi: 10.1016/S0956-5221(01)00006-9

de Laet, M. and Mol, A.M. (2000) The Zimbabwe bush pump. Mechanics of a fluid technology. Social Studies of Science, 30(2), 225-63. doi: 10.1177/030631200030002002

Langstrup Nielsen, H. (2005) Linking Healthcare. An Inquiry into the Changing Performances of Webbased Technology for Asthma Monitoring, Samfundslitteratur and Copenhagen Business School, Copenhagen.

Latour, B. (1986) Visualization and cognition: thinking with eyes and hands. Knowledge and Society, Studies in the Sociology of Culture Past and Present, 6, 1-40.

Latour, B. (1987) Science in Action: How to Follow Scientists and Engineers Through Society, Harvard University Press, Cambridge, MA.

Latour, B. (2004) The Politics of Nature, Harvard University Press, Cambridge, MA. 
Latour, B. (2005) Reassembling the Social, Oxford University Press, Oxford.

Latour, B. (2008a) What is the Style of Matters of Concern? Spinoza Lectures, The Department of Philosophy of the University of Amsterdam, Assen, Royal Van Gorcum.

Latour, B. (2008b) A cautious Prometheus? A few steps towards a philosophy of design (with special attention to Peter Sloterdijk), in Glynne, J., Hackney, F. and Minton, V. (eds.) Networks of Design: Proceedings of the 2008 Annual International Conference of the Design History Society (UK) University College Falmouth 3-6 September, pp. 2-10.

Latour, B. and Yaneva, A. (2008) Give me a gun and I will make all buildings move: an ANT's view of architecture, in Geiser, R. (ed.) Explorations in Architecture: Teaching, Design, Research, Birkhäuser, Basel, pp. 80-9.

Mol, A. (2002) The Body Multiple: Ontology in Medical Practice, Duke University Press, Durham, NC. Moser, I. (2008) Making Alzheimer's disease matter. Enacting, interfering and doing politics of nature. Geoforum, 39, 98-110. doi: 10.1016/j.geoforum.2006.12.007

Pettigrew, A. (1997) What is a processual analysis? Scandinavian Journal of Management, 13(4), 337-48. doi: 10.1016/S0956-5221(97)00020-1

Pink, S., Tutt, D. and Dainty, A. (2012) Ethnographic Research in the Construction Industry, Routledge, Abingdon.

Pui de la Bellacasa, M. (2011) Matters of care in technoscience: assembling neglected things. Social Studies of Science, 41(85), 85-106. doi: 10.1177/0306312710380301

Reijonen, S. and Tryggestad, K. (2012) The dynamic signification of product qualities: on the possibility of "greening" markets. Consumption Markets \& Culture, 15(2), 213-34. doi: $10.1080 / 10253866.2012 .654961$

Ripley, C., Thün, G. and Velikov, K. (2009) Matters of concern. Journal of Architectural Education, 62(4), 6-14. doi: 10.1111/j.1531-314X.2009.00999.x

Sage, D.J., Dainty, A.R.J. and Brookes, N. (2010) Who reads the project file? Exploring the power effects of knowledge tools in construction project management. Construction Management and Economics, 28(6), 629-639. doi: 10.1080/01446191003725154

Statens Byggeforskningsinstitut. (2012) Viden - Dokumentation - Vejledning. Til sagsbehandlere, plejepersonale og arkitekter. Pladskrave og indretning til svært overvøgtoge personer - en vejledning. The report is written in joint collaboration between Statens ByggeforskningsinstitutAalborg universitet (SBI), Odense Universitetshospital, Plambech \& Bøgedal, Social styrelsen, Nyborg kommune, by the authors: Gitte Bøgedal, Lene Plambech, Lone Sigbrand, Lars Schmidt Pedersen, Anne Christensen. Printed by: Rosendahls.

Tryggestad, K., Georg, S. and Hernes, T. (2010) Constructing buildings and design ambitions. Construction Management and Economics, 28(6), 695-705. doi: 10.1080/01446191003755441

Tryggestad, K., Justesen, L. and Mouritsen, J. (2013) Project temporalities: how frogs can become stakeholders. International Journal of Managing Projects in Business, 6(1), 69-87. doi:

10.1108/17538371311291035 
Våland, M. (2010) What We Talk about When We Talk About Space: End User Participation Between Processes of Organizational and Architectural Design, Copenhagen Business School, Copenhagen.

Van Marrewijk, A.H. (2007) Managing project culture: the case of environ megaproject. International Journal of Project Management, 25, 290-9. doi: 10.1016/j.ijproman.2006.11.004

Whatmore, S.J. (2009). Mapping knowledge controversies: science, democracy and the redistribution of expertise. Progress in Human Geography, 33(5), 587-98. doi:

10.1177/0309132509339841

Whyte, J.K., Ewenstein, B., Hales, M. and Tidd, J. (2007) Visual practices, and the objects used in design. Building Research and Information, 35(1), 18-27. doi: 10.1080/09613210601036697

Yaneva, A. (2005) Scaling up and down: extraction trials in architectural design. Social Studies of Science, 35(6), 867-94. doi: 10.1177/0306312705053053

Yaneva, A. (2008) How buildings 'surprise': the renovation of the Alte Aula in Vienna Science. Studies: An Interdisciplinary Journal of Science and Technology, 21(1), 8-29.

Funding

The UK-based research described in this paper was funded by the Engineering and Physical Sciences Research Council [Grant No. Ep/1029788/1]. 